\title{
Local Hemodynamics Dictate Long-Term Dendritic Plasticity in Peri-Infarct Cortex
}

\author{
Ricardo Mostany, ${ }^{1}$ Tara G. Chowdhury, ${ }^{1}$ David G. Johnston, ${ }^{1}$ Shiva A. Portonovo, ${ }^{1}$ S. Thomas Carmichael, ${ }^{1}$ \\ and Carlos Portera-Cailliau ${ }^{1,2}$ \\ Departments of ${ }^{1}$ Neurology and ${ }^{2}$ Neurobiology, David Geffen School of Medicine at University of California, Los Angeles, Los Angeles, California 90095
}

Changes in dendritic spine turnover are a major mechanism of experience-dependent plasticity in the adult neocortex. Dendritic spine plasticity may also contribute to functional recovery after stroke, but in that setting its expression may be complicated by alterations in local tissue perfusion, especially around the infarct. Using adult Thy-1 GFP-M mice, we simultaneously recorded long-term spine dynamics in apical dendrites from layer 5 pyramidal cells and blood flow from surrounding capillaries with in vivo two-photon microscopy in peri-infarct cortex before and after unilateral middle cerebral artery occlusion. Blood flow in periinfarct cortex decreased significantly immediately after stroke and improved gradually over time, in a distance-dependent manner from the epicenter of the infarct. However, local tissue perfusion was never fully restored even after a 3 month recovery period. On average, surviving layer 5 pyramidal neurons experienced a $\sim 20 \%$ decrease in spine density acutely after stroke but eventually recovered. The dynamics of this improvement were different depending on the degree of tissue perfusion acutely after arterial occlusion. Cells in ischemic areas closer to the infarct returned to normal spine density levels slowly by retaining spines, while cells in more remote regions with preserved blood flow recovered faster by adding more spines, eventually surpassing baseline spine density by $15 \%$. Our data suggest that maintaining tissue perfusion in the area surrounding the infarct could hasten or augment synaptic plasticity and functional recovery after stroke.

\section{Introduction}

Stroke is the third leading cause of death and the most common cause of adult disability in the United States alone (Lloyd-Jones et al., 2009). Amazingly, stroke survivors exhibit substantial recovery from their deficits (Twitchell, 1951; Skilbeck et al., 1983) which is presumably mediated by remapping of lost capabilities (e.g., language, vision, limb movement) to functionally related brain areas in both hemispheres (Chollet et al., 1991; Cao et al., 1998; Dijkhuizen et al., 2001). Structural plasticity in the brain, including neurogenesis, large-scale growth of axons and dendrites, or synaptogenesis, could mediate much of this brain rewiring (Carmichael, 2003; Zhang and Chopp, 2009). Postmortem studies in fixed tissue originally suggested that cortical lesions (including stroke) could trigger extensive dendritic plasticity in the perilesion cortex (Ito et al., 2006; Brown et al., 2008) or in the contralateral hemisphere (Jones and Schallert, 1992), but this remains controversial (Forgie et al., 1996; Biernaskie et al., 2004).

Received July 26, 2010; revised Aug. 16, 2010; accepted Aug. 19, 2010.

This work was supported by grants from the National Institute for Childhood and Developmental Disorders (to C.P.-C.), the Larry L. Hillblom Foundation (to S.T.C. and C.P.-C.), and the March of Dimes Foundation (to C.P.-C.), and by the generous support of the Fu-Hsing and Jyu-Yuan Chen Family Foundation (to C.P.-C.). We thank Drs. David Liebeskind, Josh Trachtenberg, Peyman Golshani, and Alberto Cruz-Martin for comments on the manuscript. We thank Drs. Adrian Cheng for help in setting up the laser speckle imaging system, Karel Svoboda for providing Scanlmage and spine analysis software, and Albrecht Sigler and Timothy Murphy for providing the ImageJ plugin used for laser speckle imaging analysis.

Correspondence should be addressed to Ricardo Mostany, Department of Neurology, David Geffen School of Medicine at UCLA, Reed Neurological Research Center, Room A-145, 710 Westwood Plaza, Los Angeles, CA 90095. E-mail:mostany@ucla.edu.

DOI:10.1523/JNEUROSCI.3908-10.2010

Copyright $\odot 2010$ the authors $\quad 0270-6474 / 10 / 3014116-11 \$ 15.00 / 0$
Ideally, these questions should be addressed with chronic in vivo imaging of the same neurons before and after stroke, as has been done to examine neuronal plasticity after sensory deprivation (Holtmaat and Svoboda, 2009). Long-term imaging of green fluorescent protein (GFP)-expressing pyramidal neurons in transgenic mice has demonstrated extensive synaptic remodeling after peripheral deafferentation, including increases in dendritic spine turnover and very modest increases in spine density (Trachtenberg et al., 2002; Zuo et al., 2005; Holtmaat et al., 2006; Keck et al., 2008). Qualitatively similar changes in the rate of spine additions and retractions on neurons immediately surrounding the infarct core $(<500 \mu \mathrm{m})$ have been described in the Rose Bengal photo-thrombotic stroke model (Brown et al., 2007, 2009). However, it is not known whether plasticity can extend ipsilesionally to more distant cortical regions (several $\mathrm{mm}$ away from the infarct). This is critical, because stroke typically leads to profound alterations in hemodynamics around the infarct, and more distal regions presumably have better perfusion through leptomeningeal collaterals (Schaffer et al., 2006). Therefore, it is conceivable that the potential for dendritic plasticity is greater in regions that are better perfused, but this has never been investigated.

Here, we tested this hypothesis and examined the relationship between local blood flow and dendritic plasticity in a clinically relevant model of stroke, induced by permanent unilateral middle cerebral artery occlusion (MCAO). We performed simultaneous high-resolution in vivo two-photon imaging of dendritic spines of layer (L) 5 pyramidal neurons and of local blood flow in capillaries adjacent to these dendrites in the damaged hemisphere 
over months after permanent unilateral MCAO in GFP-transgenic mice. On average, surviving neurons in peri-infarct cortex lost $20 \%$ of their spines but recovered completely over a period of 2-3 months. We found that the degree of initial tissue perfusion could predict the magnitude, rate, and mode of dendritic spine recovery. Importantly, the regions farthest away from the infarct maintained normal blood flow and eventually achieved supranormal spine density.

\section{Materials and Methods}

Animals. We used adult (3-6 months of age; male and female) C57BL/6J wild type and GFP-M transgenic mice (expressing GFP under the Thy-1 promoter) (Feng et al., 2000). All the procedures described in this study were approved by the University of California Chancellor's Animal Research Committee.

Materials. All materials were purchased from Sigma-Aldrich unless otherwise stated.

Window surgery. Chronic glass-covered cranial windows were implanted as recently described (Mostany and Portera-Cailliau, 2008b; Holtmaat et al., 2009). Mice were anesthetized with isoflurane (1.5\% via nose cone) and placed on a stereotaxic frame over a warm water recirculating blanket. Dexamethasone $(0.2 \mathrm{mg} / \mathrm{kg}$; Baxter Healthcare Corp.) and carprofen ( $5 \mathrm{mg} / \mathrm{kg}$; Pfizer Inc.) were administered subcutaneously to reduce brain edema and local tissue inflammation. A 4-mm-diameter craniotomy was performed with a pneumatic dental drill, centered of over the left hemisphere, $3 \mathrm{~mm}$ lateral to the midline and $1.95 \mathrm{~mm}$ caudal to bregma (Fig. 1a). A sterile $5 \mathrm{~mm}$ glass coverslip was gently laid over the dura mater (without using agarose) and glued to the skull with cyanoacrylate-based glue. Dental acrylic was then applied throughout the skull surface and the edges of the coverslip. A titanium bar $(0.125 \times$ $0.375 \times 0.05$ inch) was embedded in the dental acrylic to secure the mouse on to the stage of the microscope for imaging.

Distal MCAO. Unilateral distal MCAO was performed immediately after the third imaging time point (i.e., last time point for basal conditions; Fig. $1 l$ ) as previously described (Tamura et al., 1981) with some modifications. Mice were anesthetized with isoflurane and placed on a stereotaxic frame over a water recirculating blanket with the head tilted at a $45^{\circ}$ angle. The skin between the left eye and ear was incised and gently retracted, together with the temporalis muscle. The middle cerebral artery (MCA) was identified through the translucent squamosal bone ( $\sim 0.8 \mathrm{~mm}$ rostral to the anterior junction of the zygomatic and squamosal bones) and a tiny ( $0.7 \mathrm{~mm}$ in diameter) craniotomy was performed using a dental drill, $\sim 0.5 \mathrm{~mm}$ ventral to the temporal ridge. Next, the MCA was cauterized with the tip of a small forgery iron and transected with a $21 \mathrm{G}$ syringe needle. The craniotomy was then covered with a small piece of Gelfoam (Pfizer Inc.). The temporalis muscle and skin were then glued with Vetbond (3M Animal Care Products) to the temporal ridge and the acrylic cement of the headset, respectively.

Behavioral test. The limb-use asymmetry (cylinder) test (Schallert et al., 2000) was used to examine the preference for using each forelimb during recovery from MCAO. Mice were tested $1 \mathrm{~d}$ before and 1, 5, 21, and $33 \mathrm{~d}$ after MCAO. Animals were placed in a transparent glass cylinder $10 \mathrm{~cm}$ in diameter and $16 \mathrm{~cm}$ high for $10 \mathrm{~min}$ per session. Activity of the animals was recorded from above with a digital camera. Forelimb use was measured during vertical exploration counting all forepaw contacts with the cylinder. The contralateral forelimb use was calculated [i.e., contralateral forelimb/(contralateral + ipsilateral)], where 0.5 represents perfect symmetry. To compensate for preference for one paw over the other during basal conditions, forelimb use scores for every poststroke session were normalized to their respective basal value.

High-resolution in vivo two-photon imaging. Two-photon imaging began no sooner than 3 weeks after implanting the cranial window, to make sure that the cranial window surgery had no impact of the normal dynamics of dendritic spines. Indeed, we and others have shown that control mice exhibit stable spine dynamics over several months starting $10 \mathrm{~d}$ after cranial window surgery (Fig. $2 c$; supplemental Fig. 2, available at www.jneurosci.org as supplemental material) (also see Holtmaat et al., 2009).
All imaging was done with a custom-built two-channel two-photon microscope, using a Ti:Sapphire laser (Chameleon Ultra II; Coherent Inc.) tuned to $910 \mathrm{~nm}$, a $40 \times 0.8 \mathrm{NA}$ water-immersion objective (Olympus), two photomultiplier tubes (Hamamatsu) and ScanImage software written in MATLAB (MathWorks). Imaging of apical dendritic tufts of L5 pyramidal neurons within layer 1 expressing GFP was performed every $4 \mathrm{~d}$ (to match previous imaging protocols investigating spine plasticity after input deprivation) (Holtmaat et al., 2006) for the first $40 \mathrm{~d}$ (from day -8 to $+32 \mathrm{~d}$ after MCAO) and then at days $+60,+64,+90$, and +94 after MCAO (Fig. 1l). Low-magnification image stacks of sparsely labeled L5 pyramidal neurons were collected $(512 \times 512$ pixels, $0.72 \mu \mathrm{m} /$ pixel, $5 \mu \mathrm{m} z$ steps down to the soma) to confirm the identity and dendritic arborization pattern of the cells imaged. Highmagnification images $(512 \times 512$ pixels, $0.152 \mu \mathrm{m} /$ pixel, $1.5 \mu \mathrm{m} z$ steps $)$ were obtained for the analysis of dendritic spines. Imaged dendrites were in L1 (within first $100 \mu \mathrm{m}$ from pia mater). Regions of interest (ROI) containing long dendritic segments (average length $59.8 \mu \mathrm{m}$ ) of apical tufts from L5 pyramidal neurons were selected at random for chronic imaging throughout the window. All dendritic protrusions were scored, including those projecting along the $z$-axis, as long as they protruded $>0.5 \mu \mathrm{m}$ from the shaft.

Two-photon imaging of blood flow through capillaries was performed as previously described (Kleinfeld et al., 1998; Mostany and Portera-Cailliau, 2008a) at 5 time points: $1 \mathrm{~d}$ before the MCAO, and then $+1 \mathrm{~h},+9 \mathrm{~d},+20 \mathrm{~d}$, and $+90 \mathrm{~d}$ after the stroke (Fig. $1 \mathrm{l}$ ). To label the blood plasma we injected into the tail vein a $0.1 \mathrm{ml}$ bolus of a $5 \%$ w/v solution of $70 \mathrm{kDa}$ rhodamine B (stroke animals) or $500 \mathrm{kDa}$ fluorescein (control animals) as isothiocyanate-dextran conjugates dissolved in saline. Low-magnification images (as above) selected at random (control animals) or corresponding to the same areas selected for imaging dendritic structure in stroke animals were taken to identify the overall vasculature pattern and to select capillaries for blood flow imaging. Typically, $1-5$ capillaries $(<9 \mu \mathrm{m}$ in diameter) within $30 \mu \mathrm{m}$ surrounding every dendritic fragment were scanned (average $2.7 \pm 0.1$ capillaries per dendritic fragment). Then line scans (512 pixels, $0.24 \mu \mathrm{m} /$ pixel, $2 \mathrm{~ms} / \mathrm{line}$ ) along the central axis of each capillary were acquired for $1024 \mathrm{~ms}$ to analyze blood flow, resulting in $x t$ images $(122.8 \mu \mathrm{m} \times 1024 \mathrm{~ms})$. We collected $3 x t$ images per capillary at $20 \mathrm{~s}$ intervals and averaged them. Red blood cell (RBC) velocity and flux were analyzed using custom-written routines in MATLAB. For the analysis of spine density relative to tissue perfusion, we calculated the average RBC flux for all capillaries pertaining to a given cell $(8.2 \pm 4.8$ capillaries/cell) in control and stroke animals. The same dendritic and capillary regions of interest (ROIs) were located every imaging session using the unique superficial vasculature pattern on the surface of the brain as a reference (Holtmaat et al., 2009).

Laser speckle contrast imaging of blood flow. Laser speckle contrast imaging was performed as previously described (Dunn et al., 2001; Zhang and Murphy, 2007) through the cranial windows at different intervals before and after MCAO. The cortical surface was illuminated with an expanded laser diode beam ( $785 \mathrm{~nm}, 80 \mathrm{~mW}$; Thorlabs Inc.) coupled to a $600-\mu \mathrm{m}$-diameter fiber optic cable (Thorlabs Inc.). Sequences of 100 images were acquired at 30 frames per second using a fast camera (Dalsa Pantera 1 M60) with $1024 \times 1024$ pixels yielding images of $3.25 \times 3.25$ $\mathrm{mm}$. Speckle contrast images $(K=\mathrm{SD} /$ mean, $5 \times 5$ pixel area, 3.15 $\mu \mathrm{m} /$ pixel) for every frame were obtained and averaged over the 100 frames using a custom written ImageJ plugin (courtesy of Timothy Murphy, University of British Columbia, Vancouver, Canada). Relative cortical blood flow values were obtained as the ratio $K_{0}{ }^{2} / K_{\mathrm{t}}{ }^{2}$.

Analysis. Data on dendritic spine density and dynamics was obtained using spine analysis software written in MATLAB (kindly provided by Tim O'Connor and Karel Svoboda, Janelia Farm Research Campus, Ashburn, VA). We did not calculate fractions of gained or lost spines because changes in the density of spines following stroke would have influenced these numbers significantly. The survival function of dendritic spines present at day 0 (just before $\mathrm{MCAO}$ ) was obtained by fitting the survival fraction plots to a single exponential decay curve (supplemental Fig. $3 c, d$, available at www.jneurosci.org as supplemental material). Survival frac- 

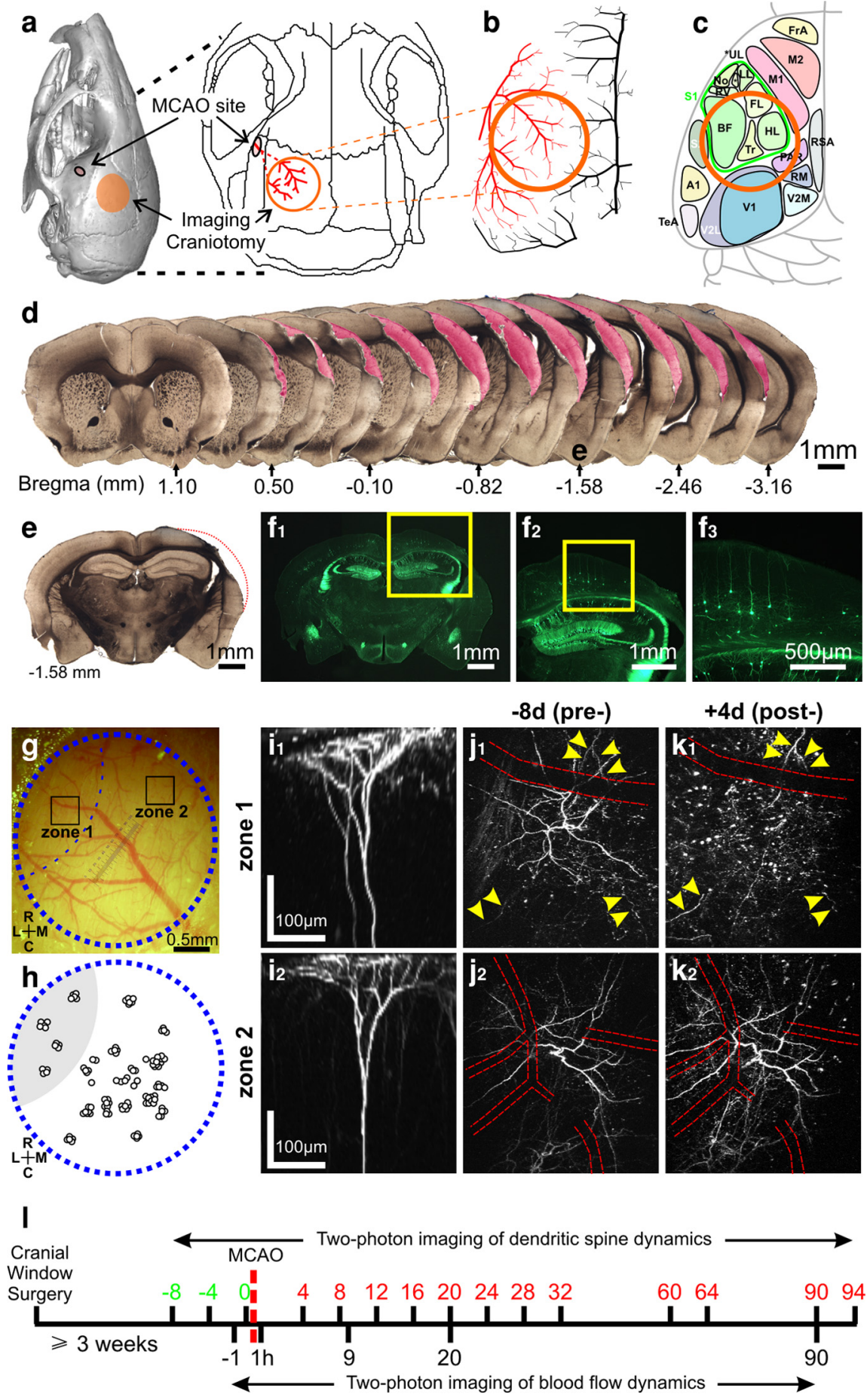

Figure 1. Unilateral permanent MCAO model of stroke and experimental design. $\boldsymbol{a}$, Location of cranial window (orange circle) and site of MCAO in relation to the structure of the adult mouse skull [left, three-dimensional side view (Image courtesy of DigiMorph.org); right, top view]. $\boldsymbol{b}$, Location of the cranial window in relationship to the MCA vascular territory (red). c, Location of the cranial window in relationship to functional brain regions (loosely based on data from Diamond et al., 1999; Paxinos and Franklin, 2001; Grove and Fukuchi-Shimogori, 2003; Van der Gucht et al., 2007). Green shading is for primary somatosensory cortex (BF, barrel field; FL, forelimb; HL, hindlimb; LL, lower lip; No, nostril; Rv, rostral vibrissae; Tr, trunk; UL, upper lip), blue shading is for visual cortex and red shading for motor cortex. $\boldsymbol{d}$, Thirteen coronal sections from a mouse in this study, showing the location and size of a representative infarct after $M C A O$ (the red shaded area represents the portions of cortex that was missing when the mouse was perfused at +94 d). $\boldsymbol{e}$, Low-magnification bright field image of a coronal section of the same GFP-M mouse. $\boldsymbol{f}$, Fluorescent photomicrographs of the same coronal section at increasing magnification (from left to right) showing the area that was chronically imaged with two-photon microscopy. $\boldsymbol{g}$, Appearance of blood vessels as seen under the cranial window (dashed circle) in a typical experiment. The typical appearance of neuronal structure in zones 1 and 2 before and after stroke are shown in higher magnification in $\boldsymbol{i}$. R, Rostral; C, caudal; L, lateral; M, medial. $\boldsymbol{h}$, Diagram of a virtual cranial window showing the location of all the dendrites imaged in this study (each circle depicts a region of interest). The shaded area in the rostral-lateral corner depicts a region tion and half-life were calculated as follows: survival fraction $=$ stable fraction + transient fraction $x \mathrm{e}^{-t / \tau}$, where $t$ is the time (days) and $\tau(\mathrm{tau})$ is the time constant; half-life $=\tau \times \ln (2)$.

In this study we tracked a total of 4147 distinct dendritic protrusions over 11-15 imaging sessions, for a total of 14,160 spines (including gained and lost spines) over $3.9 \mathrm{~mm}$ of total dendritic length in stroke animals and 2762 distinct dendritic protrusions over 9-13 imaging sessions, for a total of 10,553 spines (including gained and lost spines) over $3.0 \mathrm{~mm}$ of total dendritic length in control animals. The average length of dendritic segments analyzed in each ROI was $59.8 \mu \mathrm{m}$, and each ROI had an average of 19.1 spines at the first imaging session. We analyzed blood flow parameters from a total of 294 different capillaries (an average of 2.7 capillaries per dendritic segment in the stroke animals).

To analyze potential angiogenesis, twophoton image stacks were collected in periinfarct cortex from animals used in our spine density/blood flow experiments using the rhodamine-dextran angiography method. We quantified the number of blood vessels present in a $200 \times 200 \mu \mathrm{m}$ field of view (short $z$-stack of 3 slices, $15 \mu \mathrm{m}$ apart) at depths ranging 50-80 $\mu \mathrm{m}$ below the cortical surface before and $+90 \mathrm{~d}$ after MCAO in different animals ( $n=14$ regions; $N=6$ mice). In addition, using a different approach, the entire vasculature in $200 \times 200 \times 100 \mu \mathrm{m}(x, y$, and $z$ respectively) volume from different animals ( $n=4$ regions; $N=4$ mice) was traced and analyzed using Neurolucida (MBF Bioscience). The number of nodes (branch points) was calculated from images acquired before and at +90 $\mathrm{d}$ after stroke.

Statistics. Statistical differences of longitudinal parameters between basal and experimental conditions were calculated with Dunnett's multiplecomparisons test. A two-way ANOVA, followed by Bonferroni's multiple-comparisons test, was used to compute differences between groups (e.g., $\mathrm{BF}>70 \%$ vs $\mathrm{BF}<70 \%$ ). Extra sum-ofsquares $F$ test was used to compare the best fit values for the survival function parameters. The Kolmogorov-Smirnov test was used to compare blood flow frequency distributions. A Student's $t$ test was used to compare single parameters between two groups. All data are presented as the mean \pm SEM. Significance was set at $p<0.05$.

in which neuronal structure was reliably damaged after stroke. $\boldsymbol{i}$, Side projections $(x z)$ of image stacks (range 65-75 slices, $5 \mu \mathrm{m}$ apart) in zone 1 (top) and zone 2 (bottom) before the stroke. $\boldsymbol{j}, \boldsymbol{k}$, Maximum intensity projections of the same image stacks before $(\boldsymbol{j})$ and after $(\boldsymbol{k})$ the stroke. In general, dendrites located closest to the infarct (area 1) were destroyed. Some were still identifiable and could be used as reference landmarks (yellow arrowheads). We avoided imaging dendrites under blood vessels (red dashed line) because the GFP signal was obscured. I, Experimental design for time lapse two-photon imaging of dendrites and blood flow. 
a
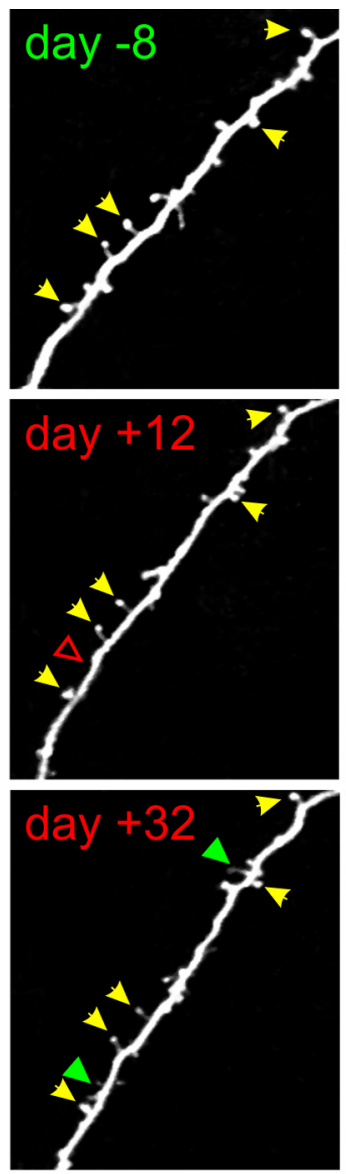

b
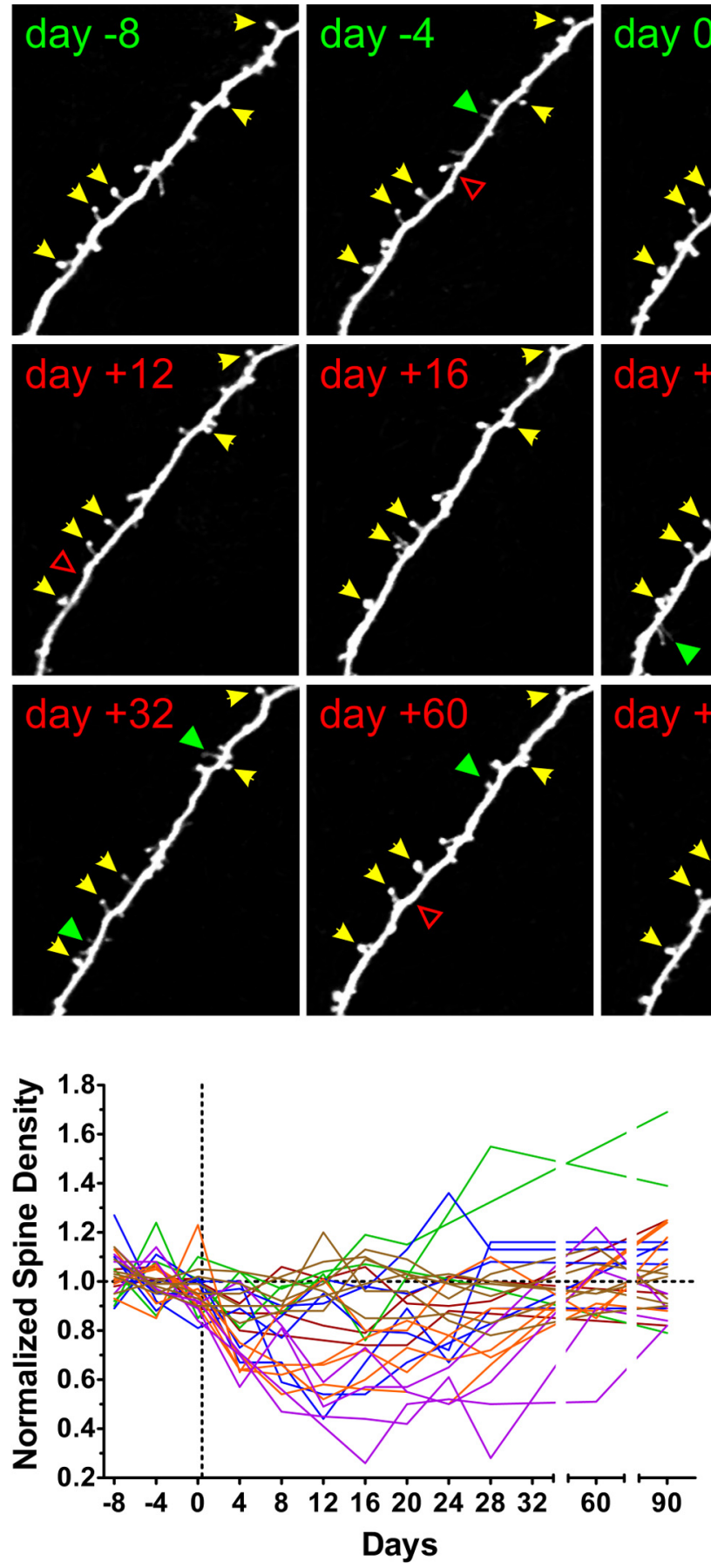
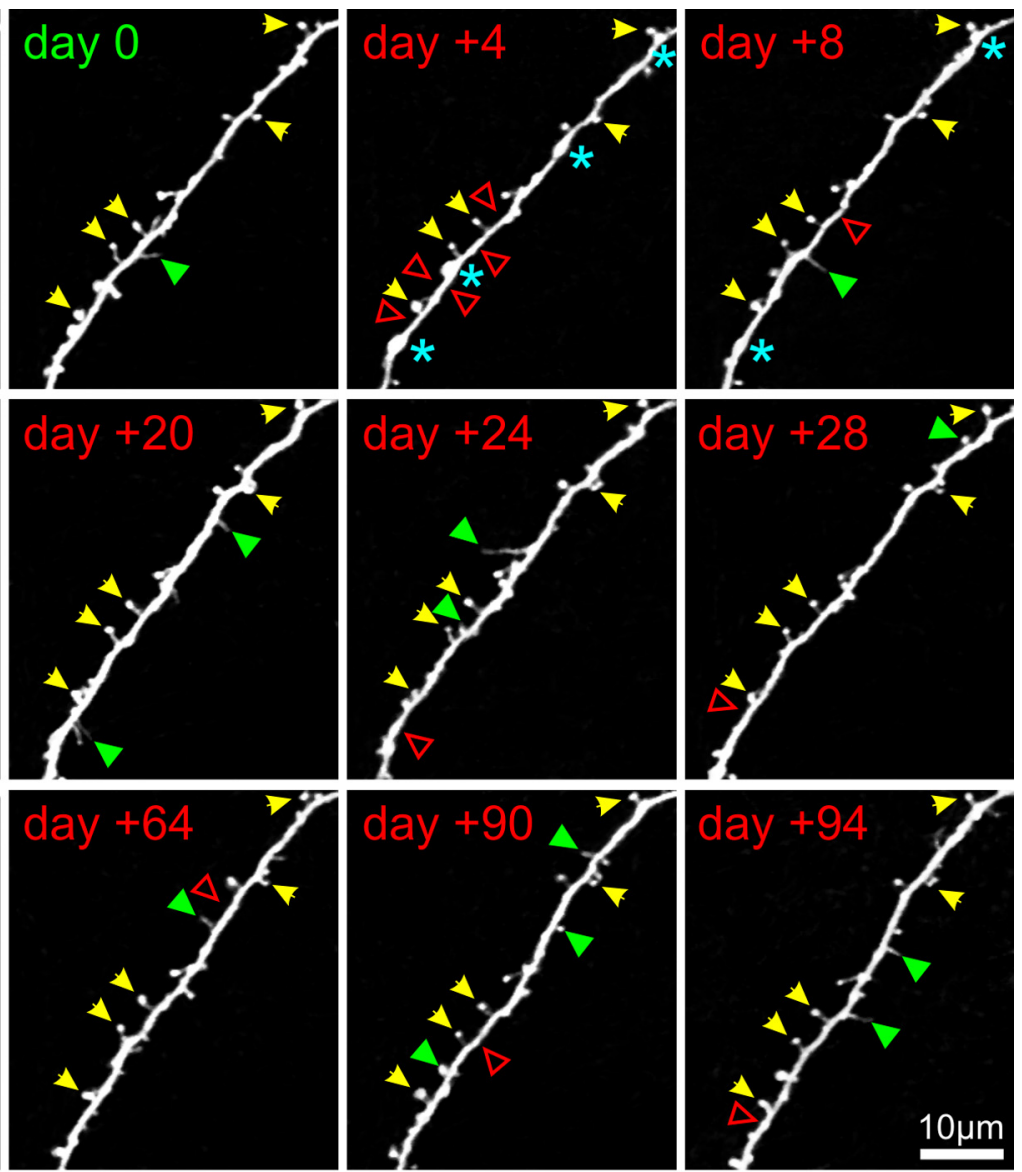

C

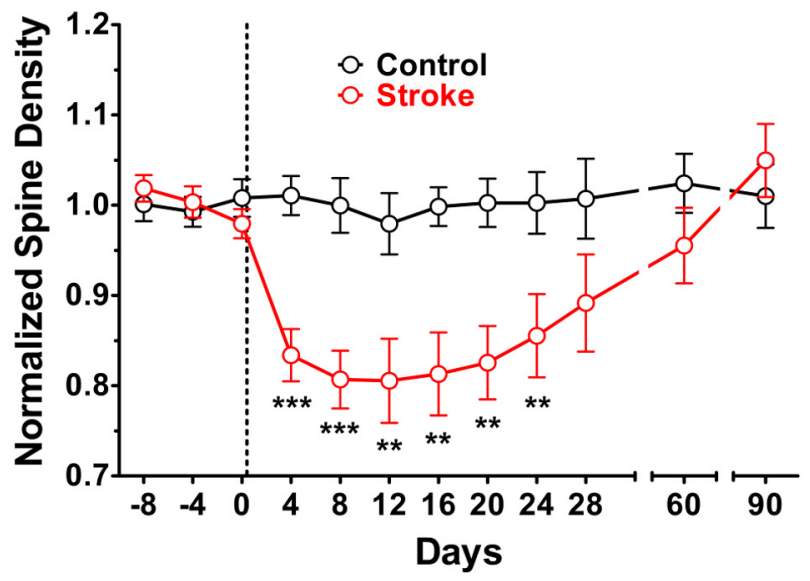

Figure 2. Chronic imaging of dendritic structure in peri-infarct cortex before and up to 3 months after MCA0. $\boldsymbol{a}$, High-resolution two-photon microscopy images acquired in vivo of an apical dendritic segment from an L5 pyramidal neuron in peri-infarct cortex. All are maximum intensity projections (4-7 slices, $1.5 \mu \mathrm{m}$ apart). A few examples of always-present spines (yellow arrows), gained spines (green arrowheads), and lost spines (open red arrowheads) are shown. The day of imaging is shown in the upper left corner. Blue asterisks at +4 and $+8 \mathrm{~d}$ post-MCA0 denote transient dendritic swelling after stroke. $\boldsymbol{b}$, Normalized spine density over time for $26 \mathrm{~L} 5$ pyramidal neurons from 6 mice. $c$, Normalized spine density averaged across neurons in stroke mice (red) and control mice (black; 22 neurons from 5 mice). Data are shown as means \pm SEM (two-way ANOVA followed by Bonferroni's multiple-comparisons test: ${ }^{* *} p<0.01 ;{ }^{* * *} p<0.001$ ). The vertical dashed line in $\boldsymbol{b}$ and $c$ indicates the time of MCAO.

\section{Results}

Acute loss and delayed recovery of dendritic spines in peri-infarct cortex

To monitor the dynamics of individual dendritic spines of L5 pyramidal neurons, we used high-resolution chronic in vivo twophoton imaging in GFP-M transgenic mice (Feng et al., 2000) through a cranial window before and after stroke. We chose a unilateral distal MCAO model of stroke (modified from Tamura et al., 1981) (Fig. 1a,b) because the mechanism of neuronal injury (ischemia from arterial occlusion) is the same as the most common stroke pattern in humans (Lloyd-Jones et al., 2009), and because it results in moderate size infarcts (Carmichael, 2005), which are proportionately similar in volume to the average stroke in humans. In addition, MCAO strokes, but not Rose Bengal photo-thrombotic strokes, are associated with a rim of periinfarct tissue with graded decreases in blood flow (Schaffer et al., 
2006), which may have an impact on the expression of neuronal plasticity.

Mice subjected to distal MCAO exhibited signs of functional impairment, as manifested by reduced use of the contralateral forelimb in the cylinder test at +1 and $+5 \mathrm{~d}$ after stroke (supplemental Fig. 1, available at www.jneurosci.org as supplemental material). Significant functional recovery was observed in affected mice by $+21 \mathrm{~d}$ poststroke. At the end of the imaging period, mice subjected to MCAO were perfused and the fixed brains processed for histology. The average infarct volume was estimated at $7.1 \pm 4.8$ $\mathrm{mm}^{3}(\sim 4.2 \%$ of cerebral cortex) (Badea et al., 2007), which included portions of the primary somatosensory cortex for the lateral barrel field, rostral vibrissae, lower lip, and forelimb, as well as a small part of the primary motor cortex (Fig. $1 c-f$ ). Thus, our MCAO model of stroke produces moderate size infarcts in anterior and lateral primary somatosensory cortex, but spares subcortical structures.

Cranial windows were deliberately implanted slightly posterior and medial to the infarct core (Fig. $1 a-h$ ). We imaged apical dendrites of L5 neurons only in peri-infarct cortex, $1-3 \mathrm{~mm}$ away from the edge of the infarct; because cells closest to the infarct underwent complete and irreversible disruption of neuronal structure immediately after MCAO (Fig. $1 g-k$ ), their dendrites could not be followed over time.

After a basal period of imaging before stroke (Fig. 1l), the distal MCA ipsilateral to the cranial window was permanently occluded. Because functional recovery in humans is nearly maximal by 3 months after stroke (Skilbeck et al., 1983), we imaged spine and blood flow dynamics for a period of 3 months after unilateral MCAO. There was a significant decrease in the spine density immediately $(+4 \mathrm{~d})$ after stroke (65 dendritic segments from $26 \mathrm{~L} 5$ neurons in 6 mice) (Fig. $1 \mathrm{l}$ ). This loss of spines peaked at $+12 \mathrm{~d}(81 \pm 5 \%$ of basal, $p<0.01)$ and was sustained for 3 weeks (Fig. 2a,c). Gradually, spine density returned to normal levels, such that by 1-2 months after MCAO we could not detect differences in normalized spine density when compared with the basal conditions, or to control animals (49 dendritic segments from 22 L5 neurons in 5 control mice) (Fig. $2 c$; supplemental Fig. 2 , available at www.jneurosci.org as supplemental material). Interestingly, the rate and magnitude of spine recovery varied from cell to cell; in general, cells that suffered greater spine losses recovered more slowly (Fig. $2 b$ ).

\section{Altered spine dynamics explain the loss and recovery of spines}

The decrease in spine density acutely after MCAO was due in part to a $47 \pm 8 \%$ (mean \pm SEM) increase in the number of lost spines $/ \mu \mathrm{m}$ and a $30 \pm 18 \%$ decrease in the number of gained spines $/ \mu \mathrm{m}$ compared with baseline (both $p<0.05$, Fig. $3 a$ ). In particular, the density of transient spines (defined as spines that were present in only one imaging session) (Holtmaat et al., 2005) was $40 \pm 9 \%$ lower right after MCAO compared with baseline ( $p<0.05$, supplemental Fig. $3 a$, available at www.jneurosci.org as supplemental material). The gradual recovery of spines was associated with a reversal in the lost/gained spine ratio during the $+16 \mathrm{~d}$ to $+32 \mathrm{~d}$ period of time (Fig. $3 b$ ). This lost/gained spine ratio returned to normal values by 2 months after the stroke. b

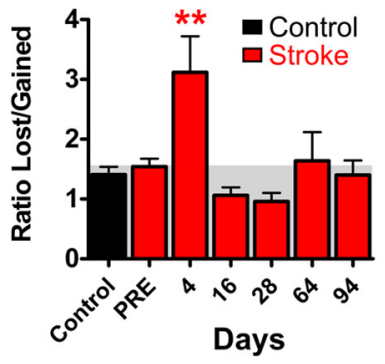

C

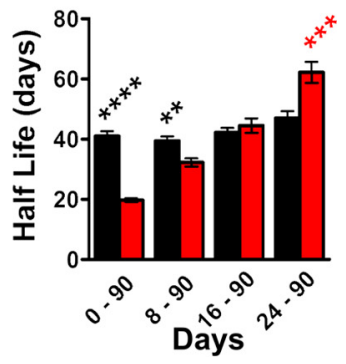
sity and/or its delayed recovery could be explained by changes in the lifetime of spines. The half-life of spines that were present on the day of MCAO (Fig. 3c) was $52 \pm 1 \%$ lower in the stroke group than in controls $(p<0.0001)$. In contrast, the half-life of spines that were present at $+24 \mathrm{~d}$ was $32 \pm 7 \%$ higher in the stroke group ( $p<0.001$, Fig. $3 c$ ). Nearly identical trends were seen in the stable fraction of spines across time after MCAO (supplemental Fig. $3 e$, available at www.jneurosci.org as supplemental material). In addition, we observed a trend toward a higher fraction of new persistent spines (defined as spines that appeared in the poststroke period and were present for at least 4 weeks) in the stroke group (supplemental Fig. $3 f$, available at www.jneurosci.org as supplemental material). Overall, these data suggest that the recovery of spines is mediated not only by an increase in the number of gained spines (relative to lost spines), but also by a relative retention or stabilization of spines after $+24 \mathrm{~d}$ poststroke.

\section{Dramatic and sustained reductions in blood flow within peri-infarct cortex}

Because the magnitude of spine loss and the rate of spine recovery were variable among different cells (Fig. 2b), we wondered whether this variability might be a reflection of changes in local tissue perfusion. Indeed, MCAO leads to a redistribution of blood flow from arterial collaterals (Coyle and Heistad, 1987; Schaffer et al., 2006; Lee et al., 2009) and this ultimately results in an infarct that is not as large as the entire MCA vascular territory at risk (Lee et al., 2009). To address this issue, we examined the relationship between dendritic spine plasticity and local hemodynamics using two independent methods: fluorescent-dextran angiography (Kleinfeld et al., 1998) and laser speckle contrast microscopy (Dunn et al., 2001).

First, we wished to clarify whether the loss of dendritic spines in peri-infarct cortex is due to acute ischemic injury or some other mechanism, such as loss of presynaptic elements from neuronal death in the infarct core. Evidence of reversible ischemic injury, similar to what has previously been reported (Takano et al., 2007; Li and Murphy, 2008), was observed even in peri-infarct cortex immediately after the MCAO and manifested as local swelling (beading) in $43.5 \%$ of dendritic segments at $+4 \mathrm{~d}$ poststroke (blue asterisks in Fig. $2 a$ and supplemental Fig. $4 a$, available at www.jneurosci.org as supplemental material). Intriguingly, there were no differences in spine density at $+4 \mathrm{~d}$ or $+8 \mathrm{~d}$ between swollen and intact dendrites (supplemental Fig. $4 b$, available at www.jneurosci.org as supplemental material), suggesting that the 

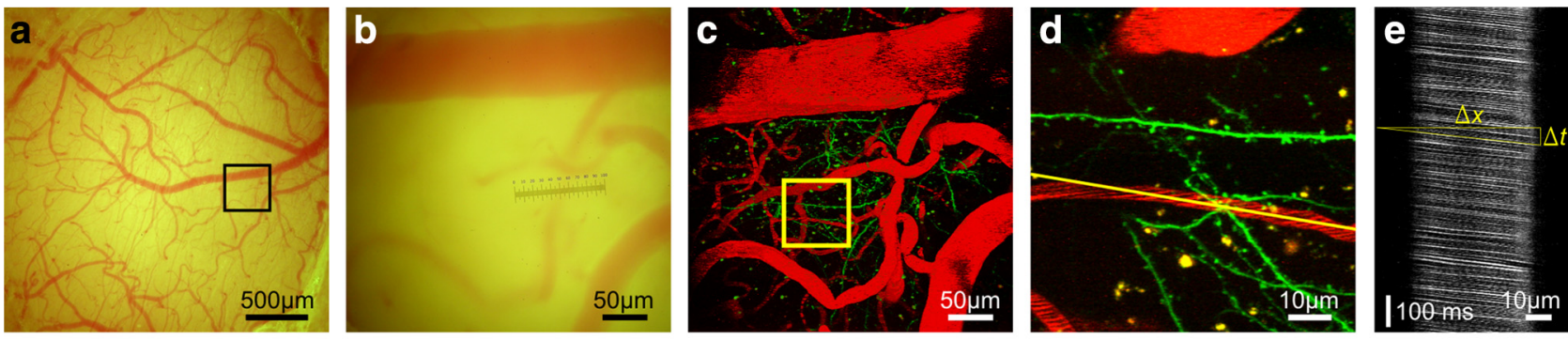

$\mathbf{f}$
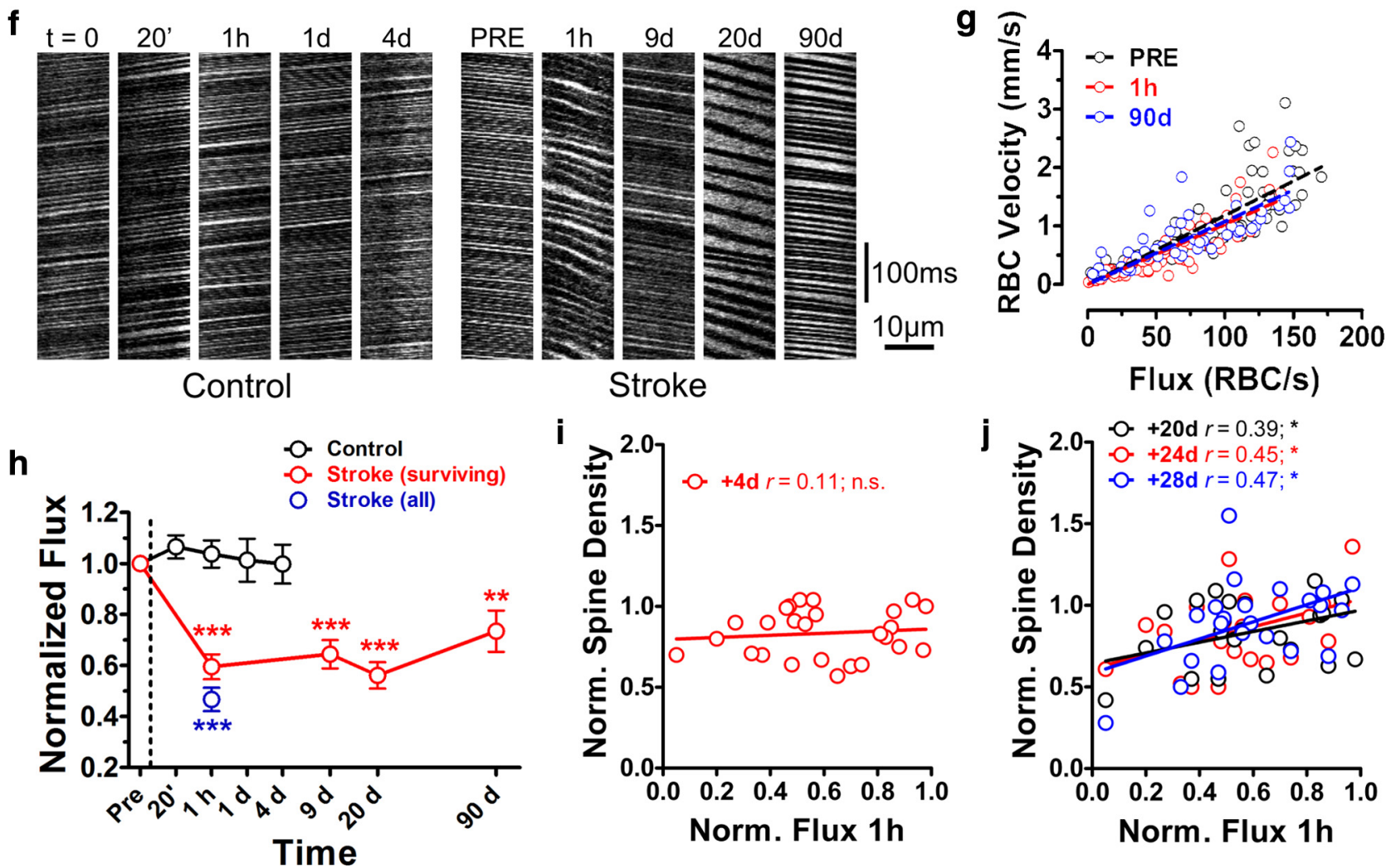

Figure 4. Dramatic and long-lasting reductions in blood flow in peri-infarct cortex. $\boldsymbol{a}$, Low-magnification view of the blood vessels on the cortical surface as seen through the glass-covered cranial window. $\boldsymbol{b}$, Higher-magnification view of the boxed region in $\boldsymbol{a}$. $\boldsymbol{c}$, Rhodamine B angiogram of the cortical vasculature (in red) corresponding to the same region shown in $\boldsymbol{b}$. GFP-expressing dendrites of $L 5$ pyramidal neurons can also be seen (green). This is a maximum intensity projection of a stack of images ( 75 slices, $5 \mu \mathrm{m}$ apart) obtained with two-photon microscopy after systemic injection of rhodamine B-dextran through the tail vein. $\boldsymbol{d}$, Higher-magnification view of the boxed region in $\boldsymbol{c}$, showing dendrites in green and a capillary in red. $\boldsymbol{e}$, Line scan ( $x t$ ) along the yellow line through the capillary shown in $\boldsymbol{d}$. Each oblique black line represents a single RBC that displaces the fluorescent dye as it travels through the capillary from left to right. From these graphs we could calculate RBC velocity as $\Delta x / \Delta t)$. $f$, Representative $x t$ line scans through a capillary in a control animal (left) at various times, and a capillary in a stroke animal (right) before (PRE) and at various intervals after MCA0. $g$, Scatter plot of RBC velocity and flux in stroke animals before (PRE), at $1 \mathrm{~h}$ after, and at $90 \mathrm{~d}$ after MCAO ( $n=74,59$, and 45 capillaries, respectively, from 3 mice). Pearson's $r=0.79,0.88$ and 0.78 , respectively $\left(p<0.001\right.$ for all datasets) between flux (RBCs/s) and velocity $(\mathrm{mm} / \mathrm{s})$. Linear densities $\rho^{-1}=11.8 \pm 0.5,10.3 \pm 0.5$, and $10.8 \pm 0.6 \mu \mathrm{m}$, respectively (n.s. between the different time points). $\boldsymbol{h}$, Normalized RBC flux for control (black) and stroke (red and blue) animals as a function of time before and after MCA0. Red trace shows data from capillaries surrounding dendritic segments from cells that were present during the whole length of the study. The blue trace also includes data from capillaries surrounding dendritic segments from cells that disappeared after the MCA0. The vertical dashed line indicates the time of MCA0. Error bars represent the SEM (Bonferroni's multiple-comparisons test: ${ }^{* *} p<0.01$; ${ }^{* * *} p<0.001$ ). $i, j$, Normalized spine density for stroke animals as a function of RBC flux at $+4 \mathrm{~d}$ after stroke (i) and for $+20,+24$, and +28 d post-MCAO (j) (Pearson's: ${ }^{*} p<0.05$ ).

acute loss of spines after stroke may not be due to direct ischemic damage to the actin cytoskeleton (see also Fig. 4i).

Next, we used two-photon line scans through capillaries filled with fluorescent-dextran dyes (Kleinfeld et al., 1998) to systematically monitor blood flow dynamics in peri-infarct cortex, in the exact same areas where we imaged dendritic spines (Fig. $4 a-f)$. Because we studied small capillaries (diameter $<9 \mu \mathrm{m}$ ) that presumably allow the transit of only one RBC at a time, we found a direct relationship between RBC flux (i.e., the number of RBCs traveling through a capillary per unit time) and $\mathrm{RBC}$ velocity at various times before and after stroke (Fig. $4 g$ ). Therefore, for the remainder of the analysis we present only data for RBC flux as an indicator of local tissue perfusion.
Control mice without MCAO showed no change in capillary RBC flux over periods of $20 \mathrm{~min}, 1 \mathrm{~h}, 1 \mathrm{~d}$, or $4 \mathrm{~d}(n=38$ capillaries in 5 mice; Fig. 4f,h). In contrast, chronic imaging of hemodynamics before and after MCAO in capillaries that could be identified throughout the whole imaging period showed a significant decrease in RBC flux surrounding the dendritic segments of interest at $+1 \mathrm{~h},+9 \mathrm{~d}$, and $+20 \mathrm{~d}$ poststroke (ranging from $56 \pm 5 \%$ to $64 \pm 5 \%$ of prestroke baseline, $p<0.001$; Fig. $4 f, h)$. The reduction in blood flow immediately after stroke (i.e., $1 \mathrm{~h}$ after MCAO) was even more pronounced when we included in the analysis capillaries that were not followed chronically beyond $+1 \mathrm{~h}$ (because they were occluded or destroyed after the stroke) (Fig. $4 h$, blue circle). In fact, blood flow never returned to normal values 
after stroke, even at $+90 \mathrm{~d}(74 \pm 8 \%$ of baseline, $p<0.01$ ). These findings were confirmed using laser speckle contrast microscopy, which demonstrated a similar magnitude of tissue hypoperfusion at +1 h (see Fig. 6d).

\section{No evidence of angiogenesis in peri-infarct cortex}

Evidence of angiogenesis within the penumbra region in experimental animal models may represent an avenue for novel therapeutic strategies in stroke (Zhang et al., 2000; Morris et al., 2003; Carmichael, 2008). Therefore, we wondered whether the partial recovery in tissue perfusion at 2 months after the stroke might be caused by the formation of new blood vessels in peri-infarct cortex. We examined this with two independent methods using our in vivo rhodamine angiography data. First, we examined short stacks of twophoton images (spanning $15 \mu \mathrm{m}$ in depth) to identify profiles of capillaries before stroke and at $+90 \mathrm{~d}$ (supplemental Fig. 5, available at www.jneurosci.org as supplemental material). We found that the density of such profiles per unit area did not change after stroke, meaning that new vessels were not observed (supplemental Fig. $5 c$, available at www.jneurosci. org as supplemental material). As a second approach, we traced with Neurolucida all blood vessels within large volumes of neocortex (stacks of 20 slices, 5 $\mu \mathrm{m}$ apart) and found no difference in the number of nodes at $+90 \mathrm{~d}$ after stroke, suggesting that no new branches had been added.

\section{Acute degree of ischemia predicts the rate and mode of recovery of spine density}

In keeping with the results for spine density in blebbed versus intact dendrites (supplemental Fig. 4, available at www. jneurosci.org as supplemental material), we found no correlation between RBC flux at $+1 \mathrm{~h}$ and spine density at $+4 \mathrm{~d}(r=0.11, p=0.59$; Fig. $4 i)$, suggesting that the degree of spine loss in peri-infarct cortex was independent of the severity of local ischemia. In contrast, there were significant positive correlations between RBC flux at $+1 \mathrm{~h}$ and dendritic spine density at $+20 \mathrm{~d},+24 \mathrm{~d}$, and $+28 \mathrm{~d}$ after MCAO ( $r=0.39,0.45$, and 0.47 , respectively; $p<0.05$ for all; Fig. $4 j$ ). We could not detect significant correlations between blood flow at later time points and spine density (data not shown), suggesting it was the blood flow acutely after stroke that predicted the ability of dendrites to recover spines, rather than the final blood flow.

To determine whether differences in local tissue perfusion after stroke might trigger different mechanisms of spine recovery, we first compared the frequency distribution of RBC flux surrounding all cells in stroke animals at $+1 \mathrm{~h}$ after MCAO and in

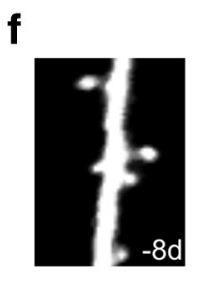

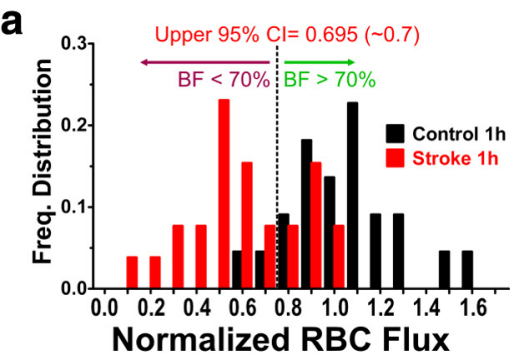
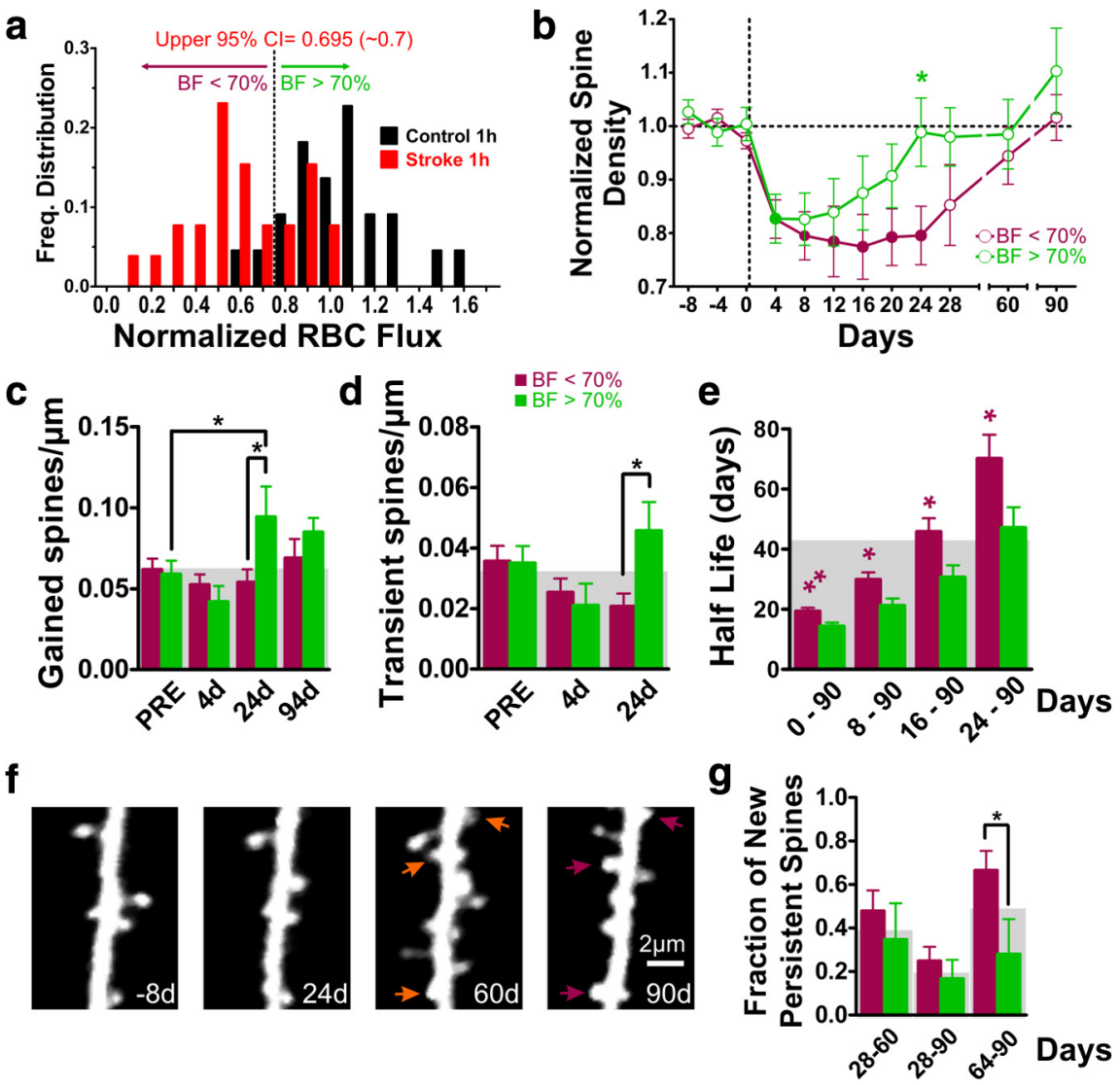

Figure 5. Acute local blood flow after stroke predicts the mode of spine recovery. $\boldsymbol{a}$, Frequency distribution of normalized RBC flux in control mice at $1 \mathrm{~h}$ time point (black) and in stroke mice at $1 \mathrm{~h}$ after MCAO (red). The upper $95 \%$ confidence interval for the exhibited average capillary RBC flux below this value (rounded to 0.7 of normal) were grouped together as regions with blood flow and those above this value were grouped as BF $>70 \%$. $\boldsymbol{b}$, Normalized spine density as a function of time before and $\mathrm{RBC}$ flux values were averaged for $1-4$ capillaries (average 2.7 per dendrite) in its immediate vicinity. Next, cells were assigned to either BF category based on the average RBC flux for all its dendritic ROls. Solid circles indicate statistically significant differences from baseline (pre-MCA0), and the asterisk $(p<0.05)$ indicates a statistically significant difference between the two BF groups two-way ANOVA followed by Bonferroni's multiple-comparisons test). c, Number of gained spines per unit length of dendrite at est; $\left.{ }^{*} p<0.05\right)$. $\boldsymbol{d}$, Number of transient spines per unit length of dendrite before (PRE) and at +4 and $+24 \mathrm{~d}$ after MCAO for the two BF groups (two-way ANOVA followed by Bonferroni's multiple-comparisons test; ${ }^{*} p<0.05$ ). $e$, Half-life of spines in the two spines (arrows) emerging at $+60 \mathrm{~d}$ on a dendrite with reduced blood flow and lasting until $+90 \mathrm{~d}$ after MCA0.g, Fraction of persistent spines appearing at various times after MCAO for the two BF groups (two-way ANOVA followed by Bonferoni's multiple-comparisons test; ${ }^{*} p<0.05$ ). Gray shading in $\boldsymbol{d}, \boldsymbol{f}$, and $\boldsymbol{h}$ shows the values in control mice without stroke. Error bars represent the SEM.

control animals $(1 \mathrm{~h})$. The distributions were strikingly different (Kolmogorov-Smirnov test, $D=-0.70, p<0.0001$, Fig. $5 a$ ), because the distribution of RBC flux in stroke animals showed two peaks, one that matched the normal distribution of blood flow in control animals, and another peak at much lower blood flow values. This suggests that some regions in peri-infarct cortex did not experience significant ischemia. Therefore, we set the upper $95 \%$ confidence interval for the RBC flux frequency distribution in the stroke animals at $1 \mathrm{~h}$ after MCAO $(95 \% \mathrm{CI}=$ $0.6954 \sim 0.70$ ) as the threshold to separate capillaries (and cells supplied by them) into two groups (Fig. $5 a, b$ ): those acutely experiencing a drastic reduction in blood flow (the "BF $<70 \%$ " group; average normalized RBC flux at $+1 \mathrm{~h}=0.43 \pm 0.03$ ) and those with only mildly reduced or normal blood flow (the "BF $>70 \%$ " group; normalized RBC flux at $+1 \mathrm{~h}=0.85 \pm 0.02$ ). 
Normalized Spine Density
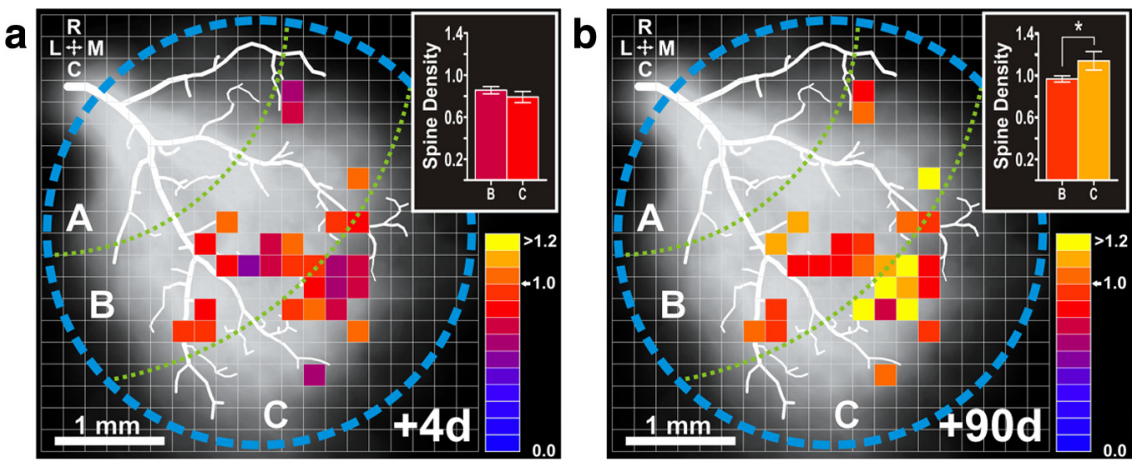

Normalized Blood Flow
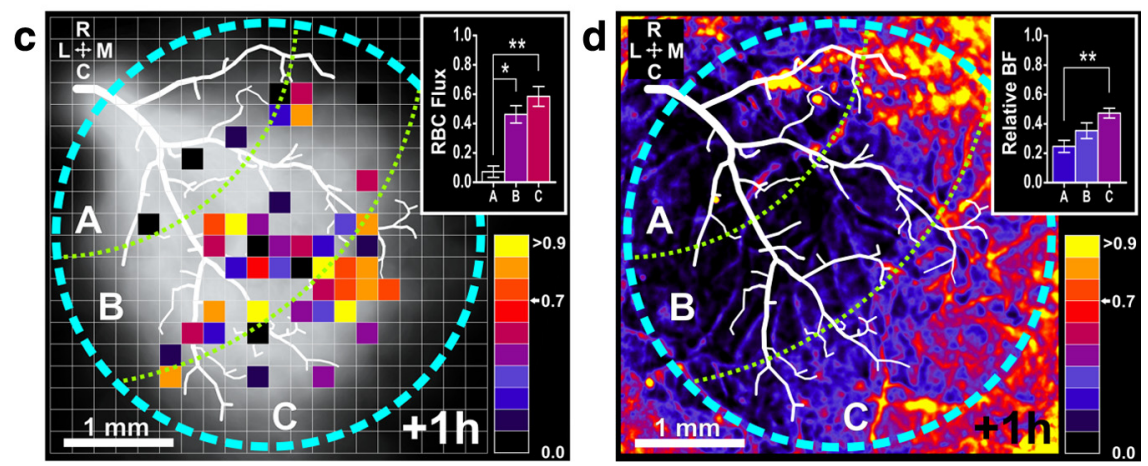

Figure 6. The magnitudes of spine recovery and local tissue perfusion correlate with distance away from infarct. In all four panels, the cranial window is shown as a blue circle. The branching pattern of a representative MCA as seen through the window is shown in white as an example. The white cloud represents the maximum intensity projection of all MCA branches in all animals imaged (controls and stroke). The generic cranial window is divided into three concentric regions, $A-C$, each $1 \mathrm{~mm}$ farther away relative to the infarct core. $\boldsymbol{a}, \boldsymbol{b}$, Normalized spine density at $+4 \mathrm{~d}(\boldsymbol{a})$ and $+90 \mathrm{~d}(\boldsymbol{b})$. Each square represents a different cell $(n=$ 26 cells, from 6 mice). When several cells overlapped in the same region, separate neighboring boxes were assigned to different cells. The color of each box reflects the normalized spine density for a given cell, according to the color map on the right. Insets depict the average spine density values \pm SEM for regions $B$ and C. Unpaired $t$ test: ${ }^{*} p<0.05$. c, RBC flux at $1 \mathrm{~h}$ after MCAO obtained by rhodamine B-dextran angiography. Each square represents the average normalized RBC flux for a given cell ( $n=258$ capillaries at $+1 \mathrm{~h}$ ). When data for two or more cells overlapped in the same region, separate neighboring boxes were assigned to different cells. The color of each box reflects the normalized RBC flux in that cell, according to the color map on the right. Inset depicts the average RBC flux values \pm SEM for regions A-C. One-way ANOVA followed by Bonferroni's comparison test: * $p<0.05$. $\boldsymbol{d}$, Relative cerebral blood flow at $+1 \mathrm{~h}$ after MCAO obtained by laser speckle contrast imaging (values are relative to baseline using the same pseudocolor scale as in c). The image represents the average relative $B F$ throughout the field of view in the cranial window obtained after transforming speckle contrast values $(K)$ to cerebral blood flow values (see Materials and Methods for details). Data from 4 different mice were superimposed and averaged onto a single image. Inset depicts the average relative BF values $\pm S E M$ for regions A-C. One-way ANOVA followed by Bonferroni's comparison test: ${ }^{* *} p<0.01$. R, Rostral; C, caudal; L, lateral; M, medial. These maps show that spine density reached levels above baseline for region C, which is farthest away from the infarct and also the one with more preserved blood flow at $+1 \mathrm{~h}$. c has more boxes than $\boldsymbol{a}$ because we could measure blood blow at $+1 \mathrm{~h}$ in more regions than we could follow dendritic structure eventually at $+4 \mathrm{~d}$.

Despite dramatic differences in degree of ischemia at $1 \mathrm{~h}$ after MCAO, both groups of cells suffered an identical decrease in normalized spine density at $+4 \mathrm{~d}(\mathrm{BF}<70 \%: 0.83 \pm 0.04$; $\mathrm{BF}>70 \%: 0.83 \pm 0.05 ; p<0.05$ for both groups vs baseline, n.s. between both groups) (Fig. $5 b$ ). Beyond the acute ischemic period, however, both groups behaved quite differently. The $\mathrm{BF}<70 \%$ group of cells had a dramatic and persistent loss of spines for $>3$ weeks ( +4 to $+24 \mathrm{~d}, p<0.05$; Fig. $5 b)$ and did not achieve baseline spine density until $+60 \mathrm{~d}$, while the $\mathrm{BF}>70 \%$ group of cells had a more rapid recovery in the density of spines, achieving basal levels by $+24 \mathrm{~d}$ (Fig. $5 b$ ).

The faster recovery of spine density in the $\mathrm{BF}>70 \%$ group was due in part to a significant increase in the number of gained spines/ $\mu \mathrm{m}$ compared with basal conditions or to the $\mathrm{BF}<70 \%$ group at $+24 \mathrm{~d}(\mathrm{BF}>70 \% 24 \mathrm{~d}: 0.094 \pm 0.019$ spines $/ \mu \mathrm{m}$ vs
BF $>70 \%$ PRE: $0.059 \pm 0.008$ spines $/ \mu \mathrm{m}$, $p<0.05$; vs $\mathrm{BF}<70 \% 24 \mathrm{~d}: 0.054 \pm 0.008$ spines/ $\mu \mathrm{m}, p<0.05$ ) (Fig. $5 c$ ). The difference was presumably due to a more than double the density of transient spines at $+24 \mathrm{~d}$ after MCAO in the group with preserved blood flow (BF>70\%: $0.046 \pm$ 0.009 spines $/ \mu \mathrm{m}$ vs $\mathrm{BF}<70 \%$ : $0.021 \pm$ 0.004 spines $/ \mu \mathrm{m}, p<0.05$ ) (Fig. $5 d$ ). In contrast, there was no difference in the number of lost spines between both groups (data not shown). Thus, spine recovery in well perfused regions was accomplished by adding more spines, especially transient ones. On the other hand, the half-life of dendritic spines from the group of cells with compromised BF was always higher than that of spines from cells in the $\mathrm{BF}>70 \%$ group (Fig. $5 e$ ). In addition, the fraction of new persistent spines born at $+64 \mathrm{~d}$ and lasting until $+90 \mathrm{~d}$ in regions with compromised blood flow was more than double that found in regions with intact blood flow (BF<70\%: $0.66 \pm$ 0.09 vs $\mathrm{BF}>70 \%$ : $0.28 \pm 0.16, p<0.05)$ (Fig. 5f,g). These findings suggest that spine recovery in acutely ischemic dendrites was achieved by retaining spines. Therefore, neurons exhibited two distinct modes of structural plasticity when recovering from stroke, depending on the degree of tissue perfusion acutely after MCAO.

\section{Areas far away from infarct core have less ischemia and reach supranormal spine densities}

In many of the neurons we imaged, dendritic spine density at $+90 \mathrm{~d}$ was higher than at baseline (Fig. 2b). Also, neurons with preserved blood flow $(\mathrm{BF}>70 \%)$ showed a trend toward a higher than normal spine density at $+90 \mathrm{~d}$, compared with those that suffered more ischemia (Fig. 5b), but this did not reach significance. We wondered whether distance from infarct might account for such variability in the magnitude of spine recovery, because blood flow may vary at different locations in the cranial window. The proximity of dendrites and capillaries to the infarct core was therefore taken into account as we mapped the spatial distribution of spine density and RBC flux throughout the cranial window. For simplicity, we divided the area of imaging into three concentric regions (centered approximately at the estimated location of the infarct core), at one millimeter radius intervals (Fig. 6, areas A-C). As mentioned above, we could not chronically image dendrites (or blood flow) in the area of the window closest to the infarct (area A). Four days after the stroke we could not detect differences in the density of spines between areas B and C ( $p=0.29$; Fig. 6a). However, by $+90 \mathrm{~d}$ after MCAO, normalized dendritic spine density in the farthest region from the infarct was $15 \pm 9 \%$ higher than baseline spine density and $19 \pm 9 \%$ higher than in areas closer to the infarct $(1.15 \pm 0.09$ in area $C$ vs $0.97 \pm 0.03$ in area $B ; p<0.05$; Fig. $6 b)$. 
In terms of blood flow, at $+1 \mathrm{~h}$ after MCAO we found significant differences in normalized RBC flux between distant areas (B and $\mathrm{C}$ ) and the region closest to the infarct, area A (A: $0.07 \pm$ 0.04; B: $0.46 \pm 0.06$; C: $0.59 \pm 0.07$ of baseline; $p<0.05$ ), but no differences between the two distant areas (Fig. $6 c$ ). This spatial pattern was confirmed when we measured large scale changes in hemodynamics over the entire cranial window with laser speckle contrast imaging (Fig. $6 d$ ). At +90 d, blood flow had partially recovered overall, but we still could not observe differences between areas B and C (data not shown). Comparing the spatial distributions of blood flow and spine density, we conclude that local tissue perfusion acutely after stroke is also correlated with the magnitude of delayed spine plasticity, as distal areas with preserved blood flow (presumably because of collateral perfusion; Coyle and Heistad, 1987) eventually achieve supranormal spine densities, while poorly perfused areas immediately adjacent to the infarct recover spine density only to prestroke baseline levels.

\section{Discussion}

Removing sensory inputs leads to alterations in dendritic spine dynamics in the cortex, a process believed to mediate experience-dependent functional changes in adult cortical circuits (Holtmaat and Svoboda, 2009). It is reasonable to assume that cortical lesions must trigger even more dramatic synaptic plasticity, because the drive for rewiring should be higher, given that the ultimate functional benefit for the animal is much greater. In the case of focal cortical injury due to ischemic stroke, the task of plasticity is complicated by the fact that peri-infarct cortex, a region that should exhibit structural plasticity because it is involved in functional remapping, has profound alterations in blood flow. We have examined this important question with chronic in vivo imaging of blood flow and dendritic structure before and after MCAO and found that the magnitude, rate and mode of synaptic plasticity in peri-infarct cortex all depend on the degree of local tissue perfusion immediately after stroke. Dendrites located in regions with relatively preserved blood flow recovered dendritic spines quickly by adding more spines, especially transient ones, while regions with compromised vascular supply recovered more slowly by retaining spines. It is conceivable that the rate and extent to which neurons in peri-infarct cortex recover spines depends on their intrinsic regenerative capacity and/or the availability of sprouting axons, growth factors and nutrients. These factors probably depend on local tissue perfusion and therefore the overall health of the affected areas. In that sense, neurons in areas farthest away from the infarct, which suffer the least ischemia, exhibited the most dramatic plasticity and eventually achieved spine densities above control levels.

Thus, the cortex compensates for loss of neurons after stroke by adding more synapses to the preexisting networks surrounding the infarct. Interestingly, recent IOS imaging experiments performed in parallel in our laboratory have revealed that functional remapping takes place in regions of peri-infarct cortex where blood flow is preserved (Mostany et al., 2009; Mostany and Portera-Cailliau, 2010). Because those are the same areas where we observed the greatest recovery in spine density, our data imply a direct link between structural dendritic plasticity and functional recovery in peri-infarct cortex.

Overall, our data on spine plasticity are consistent with results obtained by the Murphy laboratory using the focal RBPT stroke model. For example, they too found a decrease in spine density acutely after stroke, followed by gradual recovery to baseline lev- els by 6 weeks poststroke (Brown et al., 2007), as well as slightly increased weekly turnover of spines in peri-infarct cortex up to 5 weeks after stroke (Brown et al., 2009). But there are also important differences between those studies and the present one. The RBPT model results in instantaneous venous and arterial occlusion, and produces much smaller infarcts $\left(<1 \mathrm{~mm}^{3}\right)$ (Brown et al., 2007, 2009) that exhibit sharp borders between the core and the adjacent normal tissue (Zhang and Murphy, 2007). In addition, the MCAO model produces graded areas of ischemia around the infarct, whereas in RBPT strokes there is virtually no recruitment of collateral blood flow to areas surrounding the core ischemic lesion. Consequently, the Murphy group only observed alterations in dendritic spines within 100-500 $\mu \mathrm{m}$ of the infarct core (Brown et al., 2007; Enright et al., 2007), while we recorded significant alterations several mm away. Overall, our data complement those of the Murphy group by demonstrating how local hemodynamics after stroke can dictate the extent and mode of spine plasticity.

In that sense, our data suggest that improving local hemodynamics pharmacologically (via the collateral circulation) might enhance or hasten dendritic synaptic plasticity in peri-infarct cortex and could have therapeutic benefits in the clinical setting to improve recovery of lost functions. Strategies to maintain tissue perfusion in peri-infarct cortex might also enhance other modes of plasticity, such as neurogenesis, axon sprouting or the formation of new blood vessels. For example, enhancement of cerebral angiogenesis at the ischemic boundary is thought to be an essential ingredient of stroke plasticity (Zhang and Chopp, 2009) and drugs that enhance angiogenesis may prove beneficial in stroke therapy (Zhang et al., 2000). However, we did not appreciate any angiogenesis in the peri-infarct cortex. Many vessels became tortuous or thickened after stroke, but further analysis of two-photon image stacks did not reveal the de novo appearance of new capillaries deep in the cortex adjacent to the dendrites we imaged (supplemental Fig. 5, available at www.jneurosci.org as supplemental material). Although our longitudinal imaging technique offers the advantage that the same vessels could be tracked over time before and after stroke, it is possible that we missed angiogenesis taking place closer to the infarct boundary, since we inspected only capillaries at $1.3 \mathrm{~mm}$ from the infarct edge or beyond. It is possible that the absence of reperfusion in our permanent MCAO stroke model or the presence of a chronic cranial window could explain the lack of angiogenesis in our study.

The acute loss of spines after MCAO appears not to be due to ischemic injury to dendrites, and may reflect the profound deafferentation caused by loss of axons from the neighboring infarcted tissue. The identity of axons that make synapses on newly generated spines remains a mystery, but it is likely that sprouting of preexisting or new axons plays a major role $(\mathrm{Ng}$ et al., 1988; Stroemer et al., 1995). These axons could represent horizontal corticocortical connections (Carmichael et al., 2001; Dancause et al., 2005) or arise from the contralesional cortex through the corpus callosum (Brown et al., 2009). Alternatively, these axons could originate in the thalamus, which continues to receive peripheral inputs but can no longer relay them to the appropriate cortical area.

So far, we and others have only sampled a tiny portion of the cortex, the apical dendritic tufts of layer 5 pyramidal neurons, for in vivo evidence of structural plasticity after stroke. It is conceivable that other cell types could also contribute to functional recovery after stroke through axonal or dendritic plasticity and this 
should be investigated. In the future, dynamic imaging of structural and functional plasticity using a variety of fluorescent probes, combined with genetic, pharmacologic, or rehabilitative strategies, will provide additional insight into mechanisms of circuit remodeling to enhance behavioral recovery after brain injury.

\section{References}

Badea A, Ali-Sharief AA, Johnson GA (2007) Morphometric analysis of the C57BL/6J mouse brain. Neuroimage 37:683-693.

Biernaskie J, Chernenko G, Corbett D (2004) Efficacy of rehabilitative experience declines with time after focal ischemic brain injury. J Neurosci 24:1245-1254.

Brown CE, Li P, Boyd JD, Delaney KR, Murphy TH (2007) Extensive turnover of dendritic spines and vascular remodeling in cortical tissues recovering from stroke. J Neurosci 27:4101-4109.

Brown CE, Wong C, Murphy TH (2008) Rapid morphologic plasticity of peri-infarct dendritic spines after focal ischemic stroke. Stroke 39:1286-1291.

Brown CE, Aminoltejari K, Erb H, Winship IR, Murphy TH (2009) In vivo voltage-sensitive dye imaging in adult mice reveals that somatosensory maps lost to stroke are replaced over weeks by new structural and functional circuits with prolonged modes of activation within both the periinfarct zone and distant sites. J Neurosci 29:1719-1734.

Cao Y, D’Olhaberriague L, Vikingstad EM, Levine SR, Welch KM (1998) Pilot study of functional MRI to assess cerebral activation of motor function after poststroke hemiparesis. Stroke 29:112-122.

Carmichael ST (2003) Plasticity of cortical projections after stroke. Neuroscientist 9:64-75.

Carmichael ST (2005) Rodent models of focal stroke: size, mechanism, and purpose. NeuroRx 2:396-409.

Carmichael ST (2008) Themes and strategies for studying the biology of stroke recovery in the poststroke epoch. Stroke 39:1380-1388.

Carmichael ST, Wei L, Rovainen CM, Woolsey TA (2001) New patterns of intracortical projections after focal cortical stroke. Neurobiol Dis 8:910-922.

Chollet F, DiPiero V, Wise RJ, Brooks DJ, Dolan RJ, Frackowiak RS (1991) The functional anatomy of motor recovery after stroke in humans: a study with positron emission tomography. Ann Neurol 29:63-71.

Coyle P, Heistad DD (1987) Blood flow through cerebral collateral vessels one month after middle cerebral artery occlusion. Stroke 18:407-411.

Dancause N, Barbay S, Frost SB, Plautz EJ, Chen D, Zoubina EV, Stowe AM, Nudo RJ (2005) Extensive cortical rewiring after brain injury. J Neurosci 25:10167-10179.

Diamond ME, Petersen RS, Harris JA (1999) Learning through maps: functional significance of topographic organization in primary sensory cortex. J Neurobiol 41:64-68.

Dijkhuizen RM, Ren J, Mandeville JB, Wu O, Ozdag FM, Moskowitz MA, Rosen BR, Finklestein SP (2001) Functional magnetic resonance imaging of reorganization in rat brain after stroke. Proc Natl Acad Sci U S A 98:12766-12771.

Dunn AK, Bolay H, Moskowitz MA, Boas DA (2001) Dynamic imaging of cerebral blood flow using laser speckle. J Cereb Blood Flow Metab 21:195-201.

Enright LE, Zhang S, Murphy TH (2007) Fine mapping of the spatial relationship between acute ischemia and dendritic structure indicates selective vulnerability of layer $\mathrm{V}$ neuron dendritic tufts within single neurons in vivo. J Cereb Blood Flow Metab 27:1185-1200.

Feng G, Mellor RH, Bernstein M, Keller-Peck C, Nguyen QT, Wallace M, Nerbonne JM, Lichtman JW, Sanes JR (2000) Imaging neuronal subsets in transgenic mice expressing multiple spectral variants of GFP. Neuron 28:41-51.

Forgie ML, Gibb R, Kolb B (1996) Unilateral lesions of the forelimb area of rat motor cortex: lack of evidence for use-dependent neural growth in the undamaged hemisphere. Brain Res 710:249-259.

Grove EA, Fukuchi-Shimogori T (2003) Generating the cerebral cortical area map. Annu Rev Neurosci 26:355-380.

Holtmaat A, Svoboda K (2009) Experience-dependent structural synaptic plasticity in the mammalian brain. Nat Rev Neurosci 10:647-658.
Holtmaat AJ, Trachtenberg JT, Wilbrecht L, Shepherd GM, Zhang X, Knott GW, Svoboda K (2005) Transient and persistent dendritic spines in the neocortex in vivo. Neuron 45:279-291.

Holtmaat A, Wilbrecht L, Knott GW, Welker E, Svoboda K (2006) Experience-dependent and cell-type-specific spine growth in the neocortex. Nature 441:979-983.

Holtmaat A, Bonhoeffer T, Chow DK, Chuckowree J, De Paola V, Hofer SB, Hübener M, Keck T, Knott G, Lee WC, Mostany R, Mrsic-Flogel TD, Nedivi E, Portera-Cailliau C, Svoboda K, Trachtenberg JT, Wilbrecht L (2009) Long-term, high-resolution imaging in the mouse neocortex through a chronic cranial window. Nat Protoc 4:1128-1144.

Ito U, Kuroiwa T, Nagasao J, Kawakami E, Oyanagi K (2006) Temporal profiles of axon terminals, synapses and spines in the ischemic penumbra of the cerebral cortex: ultrastructure of neuronal remodeling. Stroke 37:2134-2139.

Jones TA, Schallert T (1992) Overgrowth and pruning of dendrites in adult rats recovering from neocortical damage. Brain Res 581:156-160.

Keck T, Mrsic-Flogel TD, Vaz Afonso M, Eysel UT, Bonhoeffer T, Hübener M (2008) Massive restructuring of neuronal circuits during functional reorganization of adult visual cortex. Nat Neurosci 11:1162-1167.

Kleinfeld D, Mitra PP, Helmchen F, Denk W (1998) Fluctuations and stimulus-induced changes in blood flow observed in individual capillaries in layers 2 through 4 of rat neocortex. Proc Natl Acad Sci U S A 95:15741-15746.

Lee KY, Latour LL, Luby M, Hsia AW, Merino JG, Warach S (2009) Distal hyperintense vessels on FLAIR: an MRI marker for collateral circulation in acute stroke? Neurology 72:1134-1139.

Li P, Murphy TH (2008) Two-photon imaging during prolonged middle cerebral artery occlusion in mice reveals recovery of dendritic structure after reperfusion. J Neurosci 28:11970-11979.

Lloyd-Jones D, Adams R, Carnethon M, De Simone G, Ferguson TB, Flegal K, Ford E, Furie K, Go A, Greenlund K, Haase N, Hailpern S, Ho M, Howard V, Kissela B, Kittner S, Lackland D, Lisabeth L, Marelli A, McDermott M, et al (2009) Heart disease and stroke statistics-2009 update: a report from the American Heart Association Statistics Committee and Stroke Statistics Subcommittee. Circulation 119:e21-e181.

Morris DC, Yeich T, Khalighi MM, Soltanian-Zadeh H, Zhang ZG, Chopp M (2003) Microvascular structure after embolic focal cerebral ischemia in the rat. Brain Res 972:31-37.

Mostany R, Portera-Cailliau C (2008a) A method for 2-photon imaging of blood flow in the neocortex through a cranial window. J Vis Exp 12:678.

Mostany R, Portera-Cailliau C (2008b) A craniotomy surgery procedure for chronic brain imaging. J Vis Exp 12:680.

Mostany R, Portera-Cailliau C (2010) Phenylephrine-induced hypertension prevents the loss and/or remapping of functional areas in peri-infarct cortex. Soc Neurosci Abstr 36:353.8.

Mostany R, Chowdhury TG, Johnston DG, Carmichael ST, Portera-Cailliau C (2009) Local blood flow predicts mode of dendritic plasticity in periinfarct cortex. Soc Neurosci Abstr 35:721.11.

Ng SC, de la Monte SM, Conboy GL, Karns LR, Fishman MC (1988) Cloning of human GAP-43: growth association and ischemic resurgence. Neuron 1:133-139.

Paxinos G, Franklin KBJ (2001) The mouse brain in stereotaxic coordinates, Ed 2. London: Academic.

Schaffer CB, Friedman B, Nishimura N, Schroeder LF, Tsai PS, Ebner FF, Lyden PD, Kleinfeld D (2006) Two-photon imaging of cortical surface microvessels reveals a robust redistribution in blood flow after vascular occlusion. PLoS Biol 4:e22.

Schallert T, Fleming SM, Leasure JL, Tillerson JL, Bland ST (2000) CNS plasticity and assessment of forelimb sensorimotor outcome in unilateral rat models of stroke, cortical ablation, parkinsonism and spinal cord injury. Neuropharmacology 39:777-787.

Skilbeck CE, Wade DT, Hewer RL, Wood VA (1983) Recovery after stroke. J Neurol Neurosurg Psychiatry 46:5-8.

Stroemer RP, Kent TA, Hulsebosch CE (1995) Neocortical neural sprouting, synaptogenesis, and behavioral recovery after neocortical infarction in rats. Stroke 26:2135-2144.

Takano T, Tian GF, Peng W, Lou N, Lovatt D, Hansen AJ, Kasischke KA, Nedergaard M (2007) Cortical spreading depression causes and coincides with tissue hypoxia. Nat Neurosci 10:754-762. 
Tamura A, Graham DI, McCulloch J, Teasdale GM (1981) Focal cerebral ischaemia in the rat: 1. Description of technique and early neuropathological consequences following middle cerebral artery occlusion. J Cereb Blood Flow Metab 1:53-60.

Trachtenberg JT, Chen BE, Knott GW, Feng G, Sanes JR, Welker E, Svoboda $\mathrm{K}$ (2002) Long-term in vivo imaging of experience-dependent synaptic plasticity in adult cortex. Nature 420:788-794.

Twitchell TE (1951) The restoration of motor function following hemiplegia in man. Brain 74:443-480.

Van der Gucht E, Hof PR, Van Brussel L, Burnat K, Arckens L (2007) Neurofilament protein and neuronal activity markers define regional architectonic parcellation in the mouse visual cortex. Cereb Cortex $17: 2805-2819$.
Zhang S, Murphy TH (2007) Imaging the impact of cortical microcirculation on synaptic structure and sensory-evoked hemodynamic responses in vivo. PLoS Biol 5:e119.

Zhang ZG, Chopp M (2009) Neurorestorative therapies for stroke: underlying mechanisms and translation to the clinic. Lancet Neurol 8:491-500.

Zhang ZG, Zhang L, Jiang Q, Zhang R, Davies K, Powers C, Bruggen N, Chopp M (2000) VEGF enhances angiogenesis and promotes blood-brain barrier leakage in the ischemic brain. J Clin Invest 106:829-838.

Zuo Y, Yang G, Kwon E, Gan WB (2005) Long-term sensory deprivation prevents dendritic spine loss in primary somatosensory cortex. Nature 436:261-265 